\title{
Introduction to Volume 29, Issue 3
}

\author{
Torture Journal Editorial Team*
}

We close Volume 29 with an issue of Torture Journal focused on measuring processes and results, a subject that has always been considered a priority for the sector. There is a dearth of studies on long-term follow-up to assess rehabilitation success. The paper by Martin Hill and Mary Lynn Everson, "Indicators likely to contribute to clinical and functional improvement among survivors of politically-sanctioned torture" is unique in the length of post-treatment follow-up, and provides an innovative approach in the measurement of rehabilitation outcomes through a structured measure of functional aspects with an instrument designed at the Kovler Center in Chicago. In addition, in the framework of the interminable debate over whether clinical categories of psychiatric classifications respond effectively to the experience of torture victims, Marie Louison Vang and colleagues present in their paper "Testing the validity of ICD-11 PTSD and CPTSD among refugees in treatment using latent class analysis," a validation study through multivariate models to distinguish between the classic Post-Traumatic Stress Disorder (PTSD) diagnosis and the new Complex Post-Traumatic Stress Disorder in refugee and torture survivor populations.

*) Editor-in-Chief, Torture Journal Correspondence to: pauperez@runbox.com
The results show that this new diagnosis not only complements the previous one but both approaches represent an improved nosological classification and definition of the experiences of torture survivors. Kim Baranowski and collaborators, in their paper, "Experiences of gender-based violence in women asylum seekers from Honduras, El Salvador, and Guatemala" propose, supported by the evidence gathered, that types of violence experienced by these women are multi-intersectional, and that restricted categorisation of the concept of torture can ignore the experiences of asylum-seeking women, whose lives, both in their countries of origin, in transit and in the host country, are persistently affected by structural, psychological and physical violence perpetrated by state and nonstate actors alike. Finally, Kristi Rendahl and Pamela Kriege Santoso offer in their contribution "Organizational development with torture rehabilitation programs: An applied perspective," a personal, non-data-driven text representing their experience in supporting the creation of torture victim centres in different countries within the framework of the CVT's Partners in Trauma Healing (PATH) Project.

In this last issue of the journal we would like to thank all the authors that have chosen Torture Journal as the platform to share their research. In particular, we extend 
our thanks to those anonymous reviewers who have devoted hours and effort to the indispensable task of giving us their critical and constructive view of the journal's articles. Without them the publication would not be possible.

We believe that this issue of the Torture Journal will undoubtedly provide many elements of reflection for our readers. We hope you enjoy reading it as much as we enjoyed preparing it.

Torture Journal Editorial Team 